\title{
Age and Sex Distribution of Speech Disorders
}

\author{
${ }^{1}$ Mahdi Al-Dujaily, ${ }^{2}$ Sanàa J Abu Nabàa
}

\section{ABSTRACT}

Background: Speech-language pathology is a specialty in the study, assessment, and rehabilitation of speech-language disorders (or communication disorders) which are common problems that may affect both sexes and all age groups.

Aim: The aim of this study is to raise the attention in Iraq about the role of certified speech pathologists (or speech therapists) in the treatment of patients with communication disorders according to their age and sex distribution, as seen in the phonetic center of University of Jordan.

Patients and methods: Subjects with speech problems, who visited the phonetic center in Jordan University for treatment by certified speech-language pathologists, were analyzed retrospectively during 3 years (1996 to 1998), and it included 731 subjects with speech disorders, consisted of 213 females and 518 males, with a minimum age of 2 years and a maximum age of 72 years.

Results: The most common age presentation of communication disorders varies, and it was found that the major speech and language disorders and their distribution were as follows: delayed language development occurred mainly in age group 3 to 4 years (about 57\%), stuttering occurred in 3 to 5 years (about 24\%), and in articulation disorder occurred in age group 4 to 6 years with about $42 \%$, and in hearing impaired patients occurred mainly in age group of 2 to 4 years with about $45 \%$, in children with mental retardation occurred in age group of 6 to 8 years with about 29\%, voice disorders occurred in age 20 to 29 (25\%), nasality problems in age group 3 to 5 years (25\%), dyslexia in age group 8 to 10 years (40\%), and the cases of apraxia, aphasia, and autism were low in number.

Conclusion: The age and sex distribution of communication disorders varies according to the type of disorder. The speechlanguage pathologists have very important role in the evaluation and treatment of speech language disorders. There is great deficiency of this specialty in this country, and the aim of this article is to ring the bell of attention to these common disorders.

Keywords: Communication disorders (or speech-language disorders), Speech-language pathologist, Speech therapy.

Abbreviations: SLP: Speech-language pathologist; CDs: Communication disorders; DLD: Delayed language development; HIP: Hearing impaired patient; MR: Mental retardation; $\mathrm{CP}$ : Cerebral palsy.

\footnotetext{
${ }^{1}$ Lecturer, ${ }^{2} \mathrm{Head}$

${ }^{1}$ Department of ENT, Al-Mustansiriya Medical College Baghdad, Iraq

2Department of Speech, Al-Nouras Center for Communication Disorders, Amman, Jordan
}

Corresponding Author: Mahdi Al-Dujaily, Lecturer, Department of ENT, Al-Mustansiriya Medical College, Baghdad, Iraq Phone: 009645413485, e-mail: maldujaily@hotmail.com
How to cite this article: Al-Dujaily M, Nabàa SJA. Age and Sex Distribution of Speech Disorders. Int J Phonosurg Laryngol 2015;5(1):7-14.

\section{Source of support: Nil}

\section{Conflict of interest: None}

\section{INTRODUCTION}

Speech-language pathology (or speech therapy) is a specialty in the study of speech and language, diagnosis and treatment of speech-language disorders or communication disorders (CDs) that result in communication disabilities, whereas audiology specialty is the profession concerned with the diagnosis and treatment of hearing loss. Speech-language pathologists (SLPs) (or speech therapists) are only concerned with correction of defects in speech and language resulted from hearing loss, such as delayed language development (DLD) and articulation disorders and other problems. Hearing is an important aspect of communication since it is an essential for normal acquisition of verbal communication. ${ }^{1}$ Communication disorders are common problems and if not detected and treated as early as possible may have serious effects on the individual, especially on social life and on vocational and educational aspects of the individual. For example, a male teenager with high-pitched voice (i.e. female-like voice) may be unacceptable socially, as well as a stutterer with frequent stops in his/her speech that may end the stutterer in social isolation; Schooling may also be delayed, particularly in children with severe language disorder. $^{2}$

The classification of CDs with their causes is shown in Table 1. ${ }^{1-8}$

Since 1990, the Phonetic Research Center of the University of Jordan has been committed to the development of scientific studies of speech and language disorders. It provided both academic (MSc degree in speech-language pathology) and clinical services. The Center's Clinics offer speech, language and hearing diagnostic services. The speech therapy services were provided by licensed professional speech-language pathologists who help persons with CDs in children and adults to overcome their problems.

During my work in the Phonetic Center of the Jordan University, as a medical and audiological supervisor, from 1994 to 2000, I analyzed retrospectively the types 
Table 1: Classification of communication disorders and causes ${ }^{1-8}$

\begin{tabular}{|c|c|}
\hline Speech disorder & Causes \\
\hline Language & In children \\
\hline Morphological deficits/ & Developmental language disorder, environmental \\
\hline Syntactic deficits/ & deprivation, psychological disturbances, \\
\hline Semantic deficits/ & congenital syndrome (e.g. Down syndrome), diseases \\
\hline \multirow[t]{6}{*}{ Pragmatic deficits } & (meningitis), hearing loss, head injury, visual \\
\hline & impairment, muscle control problem (cerebral palsy), \\
\hline & cleft palate, auditory processing disorder (central), \\
\hline & autism \\
\hline & In adults \\
\hline & Stroke, head injury, neurological diseases \\
\hline Articulation/phonology & Functional \\
\hline $\begin{array}{l}\text { Substitution/ } \\
\text { Omissions/ } \\
\text { Additions/ } \\
\text { Distortions }\end{array}$ & Organic: Cleft palate, hearing impairment, developmental speech apraxia \\
\hline Fluency: Stuttering, cluttering & $\begin{array}{l}\text { Unknown (probably neuromuscular abnormalities, may be contributed by stress and } \\
\text { learned factors). }\end{array}$ \\
\hline \multirow[t]{5}{*}{ Voice and/or resonance } & $\begin{array}{l}\text { - Functional: Abuse/misuse, vocal nodules, contact ulcer, ventricular dysphonia, } \\
\text { psychogenic. }\end{array}$ \\
\hline & $\begin{array}{l}\text { - Organic: Vocal cord paralysis, laryngeal webs, papillomas, reinke edema, tumor, } \\
\text { granuloma, neurologic, endocrine disease. }\end{array}$ \\
\hline & - Spasmodic dysphonia (unknown etiology). \\
\hline & - Velopharyngeal dysfunction: Cleft palate \\
\hline & - Laryngectomy \\
\hline Neurologically based & - Stroke \\
\hline - Adult aphasia: & - Traumatic brain injury \\
\hline $\begin{array}{l}\text { - Fluent: Wernicke's, Conduction, } \\
\text { Anomic. }\end{array}$ & - Brain tumors \\
\hline $\begin{array}{l}\text { - Non-fluent: Broca's, Transcortical } \\
\text { motor, Global. }\end{array}$ & - Brain surgery \\
\hline - Apraxia: & - Brain infections \\
\hline - Speech apraxia: Developmental/ & - Other neurological diseases: Alzheimer’s disease, \\
\hline nondevelopmental & Multiple sclerosis, cerebral palsy, \\
\hline - Oral apraxia & Bulbar palsy, pseudobulbar palsy, \\
\hline - Limb apraxia & Cerebellar, Parkinsonism, \\
\hline - Dysarthrias: & Extrapyramidal lesions \\
\hline $\begin{array}{l}\text { Flaccid; spastic, ataxic, hypokinetic, } \\
\text { hyperkinetic }\end{array}$ & - Causes of apraxias: neurological (not well understood) \\
\hline Autism & Unknown \\
\hline Hearing & ConductivelSensori-neurallmixed \\
\hline Mental retardation & \\
\hline
\end{tabular}

of speech problems with their age and sex distribution, which were evaluated and treated by SLPs of the center. The aim of this paper is to raise the attention of age and sex distribution of various speech disorders, treated by SLPs in the phonetic center, due the deficiency of this specialty in this country.

\section{PATIENTS AND METHODS}

Every patient with speech problem visited the phonetic center was given an appointment for speech and language evaluation, which may require more than one session, and it is, usually, preceded by a hearing test to exclude hearing loss, with the aim of diagnosing the speech problem. There were evaluations questionnaires for main speech disorders, such as language, articulation, stuttering, aphasia and voice disorders. When speech problem of the patient was diagnosed, the patient was then given a schedule of speech therapy program which consisted of 2 to 3 sessions or more per week, and each session lasted about 50 minutes. 
Seven hundred and thirty-one speech problem cases were seen in the years 1996,1997, and 1998, and they were distributed as 213 females and 518 males with a minimum age of 2 years and a maximum age of 72 years.

\section{RESULTS}

The results, as shown in Graph 1 and Table 2, revealed that DLD, stuttering, articulation, and hearing impaired

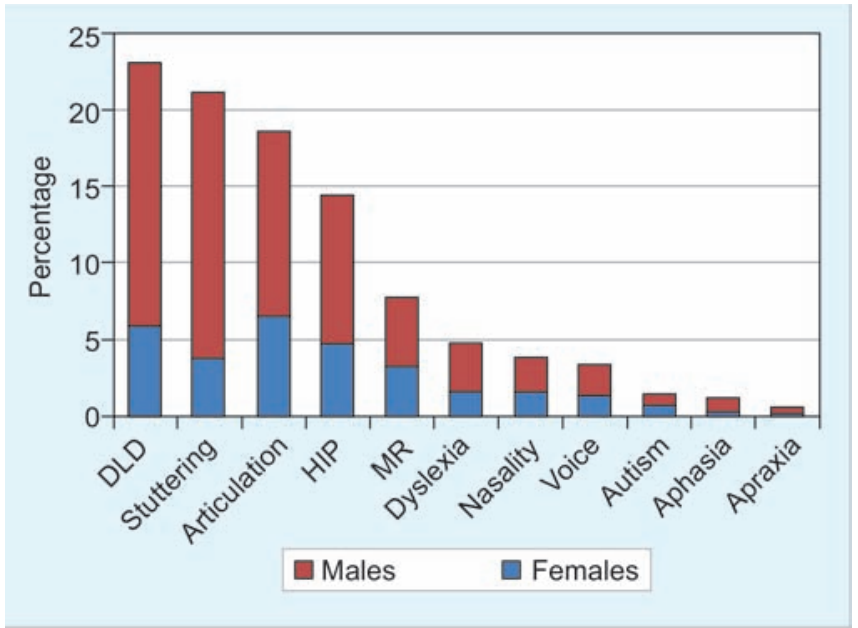

Graph 1: Percents of speech-language disorders with sex distribution

Table 2: Number, percents and sex distribution of speech disorders

\begin{tabular}{|c|c|c|c|c|c|c|}
\hline \multirow{2}{*}{$\begin{array}{l}\text { Speech } \\
\text { disorders }\end{array}$} & \multicolumn{2}{|c|}{ Females } & \multicolumn{2}{|c|}{ Males } & \multicolumn{2}{|c|}{ Grand total } \\
\hline & No. & $\%$ & No. & $\%$ & No. & $\%$ \\
\hline DLD & 43 & 5.9 & 126 & 17.2 & 169 & 23.1 \\
\hline Stuttering & 27 & 3.7 & 128 & 17.5 & 155 & 21.2 \\
\hline Articulation & 47 & 6.4 & 90 & 12.3 & 137 & 18.7 \\
\hline HIPs & 34 & 4.7 & 71 & 9.7 & 105 & 14.4 \\
\hline MR & 23 & 3.2 & 33 & 4.5 & 56 & 7.7 \\
\hline Nasality & 11 & 1.5 & 17 & 2.33 & 28 & 3.83 \\
\hline Voice & 9 & 1.23 & 15 & 2.04 & 24 & 3.28 \\
\hline Dyslexia & 11 & 1.5 & 24 & 3.3 & 35 & 4.8 \\
\hline Autism & 5 & 0.7 & 5 & 0.7 & 10 & 1.4 \\
\hline Aphasia & 2 & 0.27 & 6 & 0.82 & 8 & 1.09 \\
\hline Apraxia & 1 & 0.14 & 3 & 0.41 & 4 & 0.55 \\
\hline Grand total & 213 & 29.1 & 518 & 70.9 & 731 & 100 \\
\hline
\end{tabular}

patients (HIPs) constituted about three-quarters of all CDs with a percents of 23, 21, 19 and 14 respectively. The rest of CDs included mental retardation (MR) $(8 \%)$, voice/ nasality problem $(7 \%)$, dyslexia $(5 \%)$, cases of apraxia/ aphasia $(2 \%)$ and autism ( $1 \%)$. It was also noted that more speech problems are seen in males than females and generally, accounted for more than two times in most of speech disorders, and may reach 3 times in DLD and about 5 times in stuttering. Tables 3 to 5 show the age distribution in all cases of $\mathrm{CDs}$, where the $\mathrm{CD}$ cases of DLD, stuttering, articulation, HIPs, were represented in Table 3, and the cases of MR, voice, nasality, and dyslexia were shown in Table 4, and for CDs of aphasia, apraxia and autism were shown in Table 5 respectively.

Graph 2 and Table 3 showed the age distribution of cases of DLD which ranged in ages between 2 and 8 years, and most of the cases were in the preschool age group of 3 to 5 years, constituting about $70 \%$ of the total number of DLD cases. Cases with stuttering speech problem were shown in Graph 4 and Table 3, which showed that the peak of cases were in the preschool age of 3 to 5 years, and constituted about a quarter of the cases, and about $50 \%$ of the cases were in the school

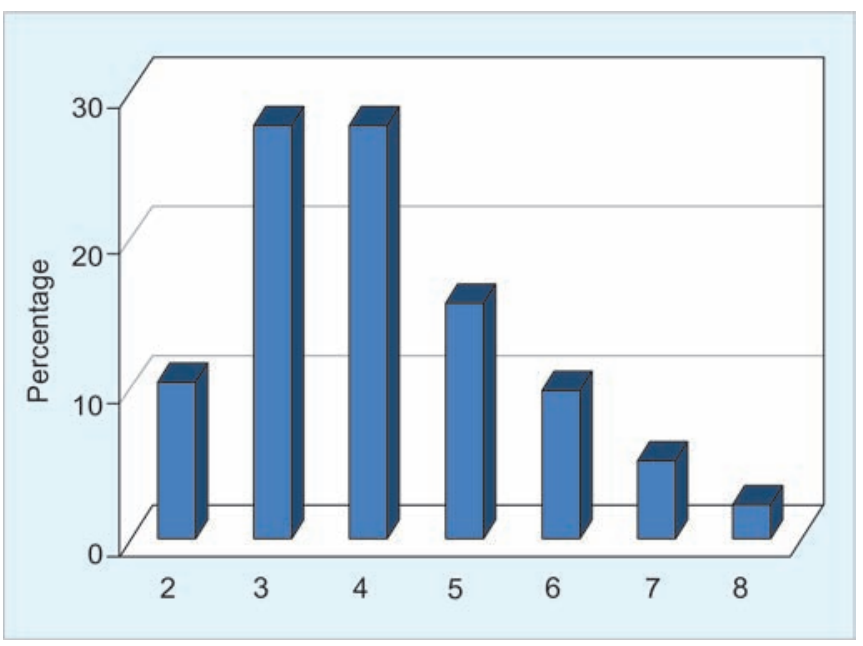

Graph 2: Age distribution of delayed DLD cases

Table 3: Age distribution of speech disorders: DLD, stuttering, articulation and HIPS

\begin{tabular}{|c|c|c|c|c|c|c|c|c|c|c|c|}
\hline \multicolumn{3}{|c|}{$D L D$} & \multicolumn{3}{|c|}{ Stuttering } & \multicolumn{3}{|c|}{ Articulation } & \multicolumn{3}{|c|}{ HIPS } \\
\hline Age (yrs) & No. & $\%$ & Age (yrs) & No. & $\%$ & Age (yrs) & No. & $\%$ & Age (yrs) & No. & $\%$ \\
\hline 2 & 18 & 10.7 & $3-5$ & 37 & 23.9 & $4-6$ & 57 & 41.6 & $2-4$ & 47 & 44.8 \\
\hline 3 & 47 & 27.8 & $6-8$ & 25 & 16.1 & $7-9$ & 37 & 27.0 & $5-7$ & 38 & 36.2 \\
\hline 4 & 47 & 27.8 & $9-11$ & 27 & 17.4 & 10-12 & 18 & 13.1 & $8-10$ & 12 & 11.4 \\
\hline 5 & 27 & 15.9 & $12-14$ & 24 & 15.5 & $13-15$ & 4 & 2.9 & $11-13$ & 1 & 0.9 \\
\hline 6 & 17 & 10.1 & $15-17$ & 12 & 7.7 & $16-18$ & 2 & 1.5 & 14-16 & 3 & 2.9 \\
\hline 7 & 9 & 5.3 & $18-20$ & 9 & 5.8 & $19-21$ & 8 & 5.8 & $17-19$ & 1 & 0.9 \\
\hline \multirow[t]{4}{*}{8} & 4 & 2.4 & $21-23$ & 12 & 7.7 & $22-24$ & 4 & 2.9 & 20-22 & 1 & 0.9 \\
\hline & & & 24-26 & 5 & 3.2 & $25-27$ & 2 & 1.5 & 23-25 & 2 & 1.9 \\
\hline & & & 27-29 & 3 & 1.9 & 28-30 & 3 & 2.2 & & & \\
\hline & & & $30-32$ & 1 & 0.7 & $31-33$ & 2 & 1.5 & & & \\
\hline Total & 169 & 100 & & 155 & 100 & & 137 & 100 & & 105 & 100 \\
\hline
\end{tabular}


Table 4: Age distribution of speech disorders: MR, voice, nasality and dyslexia

\begin{tabular}{|c|c|c|c|c|c|c|c|c|c|c|c|}
\hline \multicolumn{3}{|c|}{$M R$} & \multicolumn{3}{|c|}{ Voice } & \multicolumn{3}{|c|}{ Nasality } & \multicolumn{3}{|c|}{ Dyslexia } \\
\hline Age (yrs) & No. & $\%$ & Age (yrs) & No. & $\%$ & Age (yrs) & No. & $\%$ & Age (yrs) & No. & $\%$ \\
\hline $3-5$ & 10 & 17.9 & $0-9$ & 2 & 8.3 & $3-5$ & 7 & 25.0 & $5-7$ & 8 & 22.9 \\
\hline $6-8$ & 16 & 28.6 & 10-19 & 5 & 20.8 & $6-8$ & 6 & 21.4 & $8-10$ & 14 & 40.0 \\
\hline 9-11 & 11 & 19.6 & 20-29 & 6 & 25.0 & $9-11$ & 4 & 14.3 & 11-13 & 8 & 22.9 \\
\hline $12-14$ & 10 & 17.9 & 30-39 & 5 & 20.8 & $12-14$ & 4 & 14.3 & $14-16$ & 2 & 5.7 \\
\hline 15-17 & 3 & 5.4 & $40-49$ & 3 & 12.5 & $15-17$ & 2 & 7.1 & 17-19 & 1 & 2.9 \\
\hline \multirow[t]{3}{*}{$18-20$} & 6 & 10.7 & $50-59$ & 2 & 8.3 & $18-20$ & 3 & 10.7 & $20-22$ & 1 & 2.9 \\
\hline & & & $60-69$ & 1 & 4.2 & $21-23$ & 1 & 3.6 & 29-31 & 1 & 2.9 \\
\hline & & & & & & $24-26$ & 1 & 3.6 & & & \\
\hline Total & 56 & 100 & & 24 & 100 & & 28 & 100 & & 35 & 100 \\
\hline
\end{tabular}

Table 5: Age distribution of speech disorders: aphasia, apraxia and autism

\begin{tabular}{|c|c|c|c|c|c|c|c|c|}
\hline \multicolumn{3}{|c|}{ Aphasia } & \multicolumn{3}{|c|}{ Apraxia } & \multicolumn{3}{|c|}{ Autism } \\
\hline Age (yrs) & No. & $\%$ & Age (yrs) & No. & $\%$ & Age (yrs) & No. & $\%$ \\
\hline 35 & 1 & 12.5 & 6 & 1 & 25 & $2-4$ & 1 & 10 \\
\hline 52 & 1 & 12.5 & 7 & 2 & 50 & $5-7$ & 2 & 20 \\
\hline 54 & 1 & 12.5 & 40 & 1 & 25 & 8-10 & 2 & 20 \\
\hline 57 & 1 & 12.5 & & & & $11-13$ & 2 & 20 \\
\hline 60 & 2 & 25.0 & & & & 14-16 & 3 & 30 \\
\hline 64 & 1 & 12.5 & & & & & & \\
\hline 72 & 1 & 12.5 & & & & & & \\
\hline Total & 8 & 100 & & 4 & 100 & & 10 & 100 \\
\hline
\end{tabular}

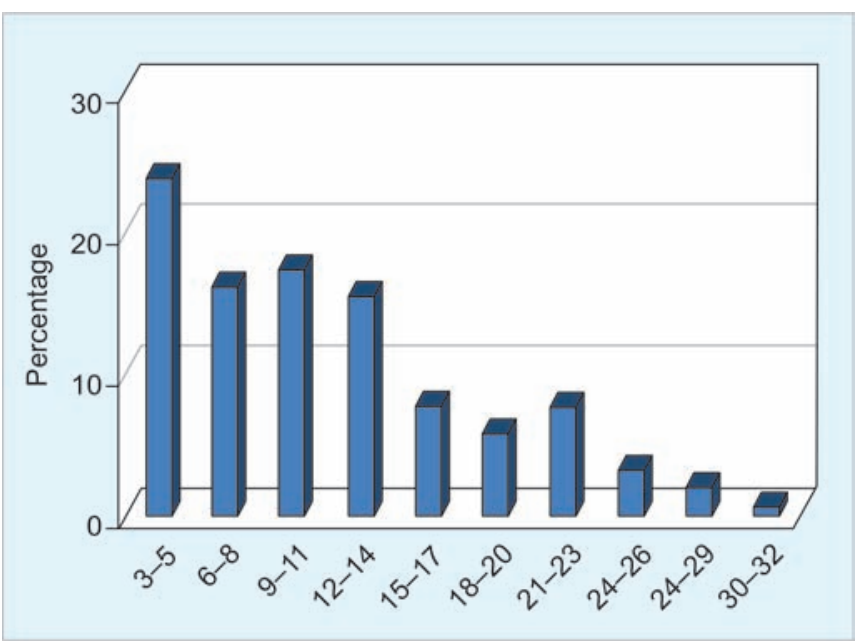

Graph 3: Age distribution of stuttering cases

age of 6 to 14 years. Rest of the cases were scattered in the age range of 15 to 32 years. The age distribution of articulation and phonological process disorders is shown in Graph 5 and Table 3. Forty percent of the cases fall in the preschool and school entry ages of 4 to 6 years, and a similar percent in the age range of 7 to 12 years. Rest of the cases were spread over a wide range of ages up to the age of 33 years; most these had speech problem with one or two sounds production, e.g. the ' $r$ ' and 's' sounds. Speech problems due to hearing loss are shown in Graph5 and Table 3, which are usually have features of DLD and disorder of articulation speech sound production. Most

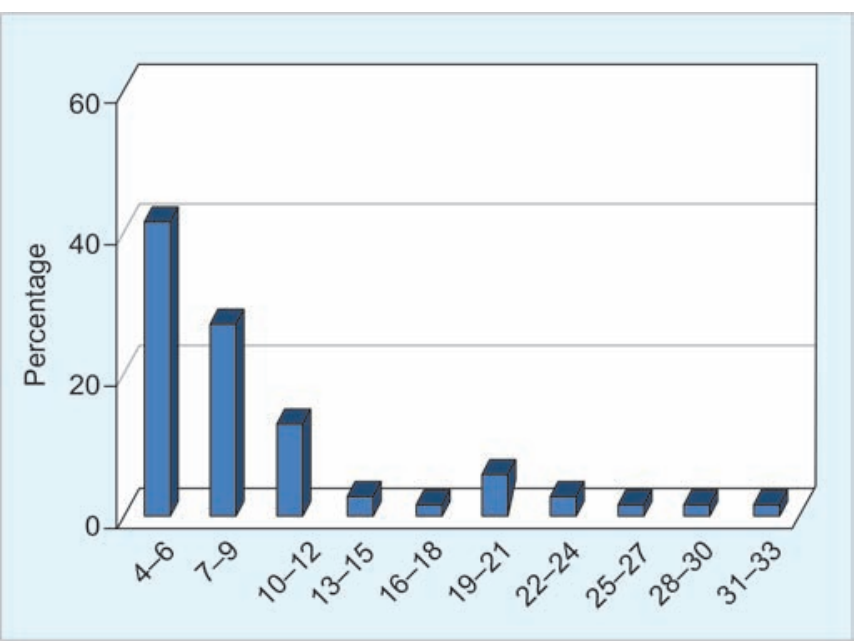

Graph 4: Age distribution of articulation/phonological cases

of the HIP children constitute collectively about $90 \%$ of cases in the three age groups of 2 to 4 years, 5 to 7 years and 8 to 10 years which forms separately about 45,35 and $10 \%$ respectively. These children were usually fitted with hearing aids before speech therapy. Graph 6 and Table 4 show the age distribution of the mentally retarded patients who received speech therapy. Most of these cases were of Down syndrome manifested by language and articulation disorders. Problems with voice and nasality cases are shown in Graphs 7 and 8 respectively and Table 4 including vocal nodules, dysphonia and puberphonia affecting mainly the middle age group and the 


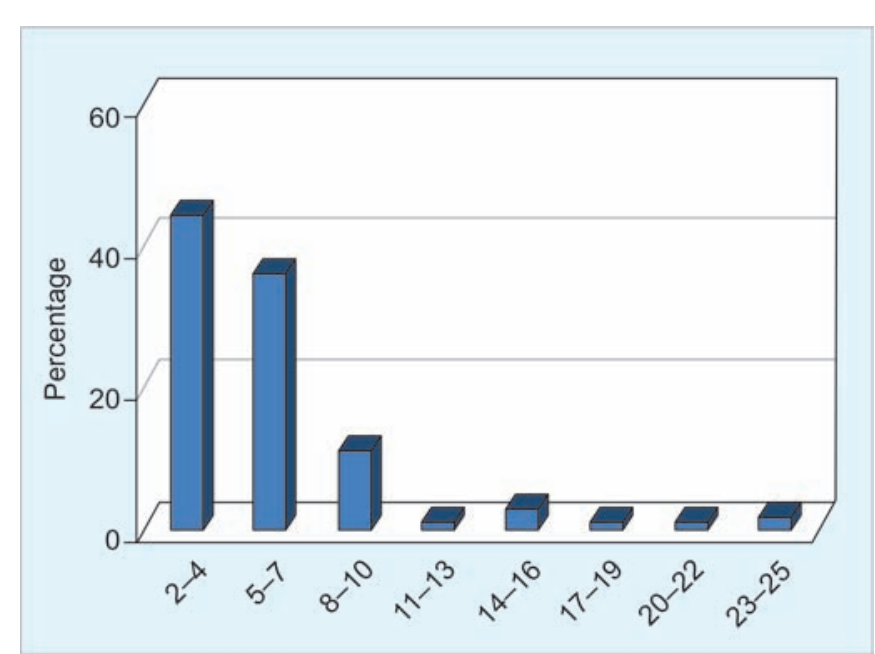

Graph 5: Age distribution of hearing-impaired patients with speech problems

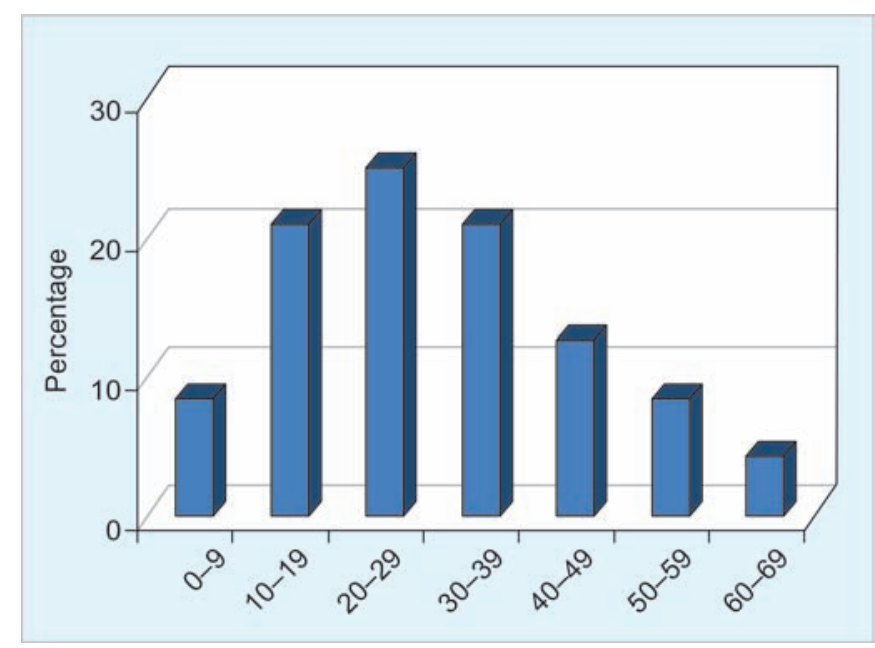

Graph 7: Voice cases excluding nasality cases (24 in number)

nasality problem due to cleft palate with percentages of 25 and 20 in the age groups 3 to 5 and 6 to 8 respectively. Also, the SLPs treated cases with reading and writing difficulty, most of them in the school age of 5 to 13 years, as shown in Graph 9 and Table 4. Cases with aphasia, apraxia or dysarthria were few relative to the other speech disorders as shown in Graph 10 and Table 5. Finally, cases among the autistic spectrum were also low in number, were seen by speech language pathologists who combine behavior and language therapy in the treatment of these cases (Graph 11).

\section{DISCUSSION}

In USA, about $32 \%$ of children diagnosed with communication disorders in school age have articulation/phonological disorders, and about $75 \%$ of pre-school children with articulation/phonological disorders have also additional language disorders. ${ }^{3}$ In another survey on primary school students, in Australia, the prevalence of students diagnosed as articulation disorder was $1.06 \%$, children

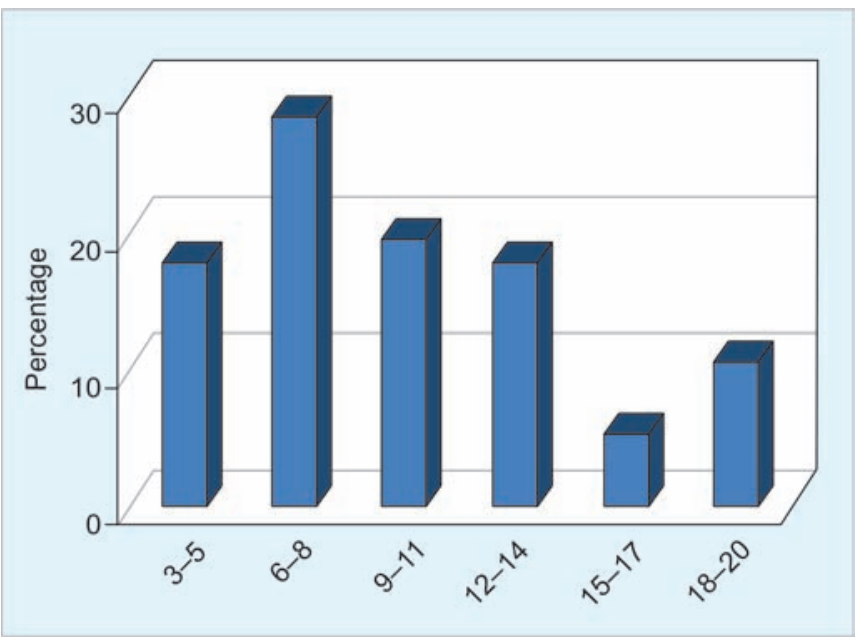

Graph 6: Age distribution of mentally retarded cases

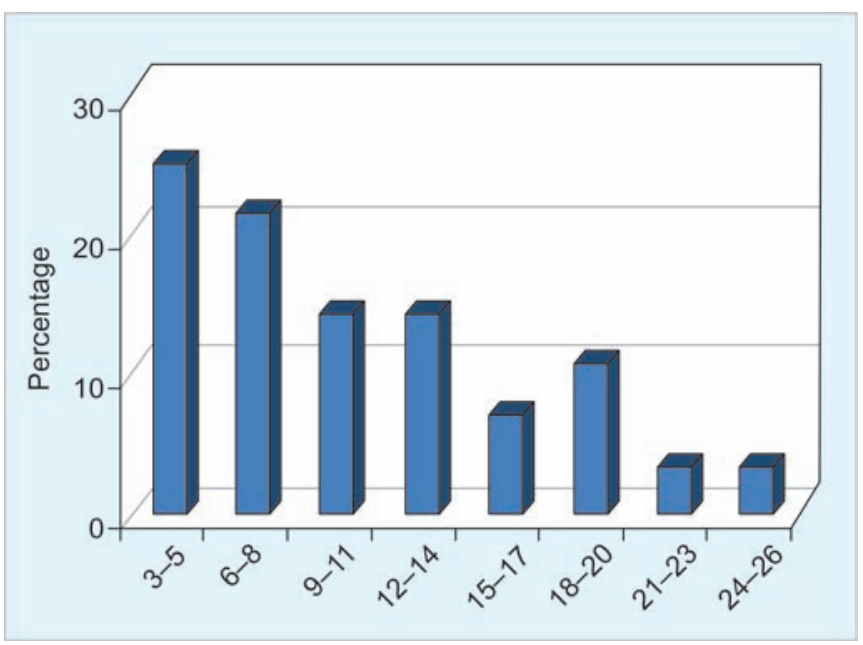

Graph 8: Nasality cases (28 in number)

with stuttering was $0.33 \%$, and with voice disorders was $0.12 \%$, with higher males to female ratios. ${ }^{9}$ The types of CDs in the elderly subjects differ from that in children, and it was found that $51 \%$ of the elderly subjects living in nursing homes have CDs, which included $21 \%$ voice disorders, $19 \%$ articulation disorders and 11\% aphasia disorders. ${ }^{1}$

In this study, DLD constituted the highest percentage of CDs forming about $23 \%$, and such higher results of language disorders were also reported in other studies, with more in boys than girls. ${ }^{3,10,11}$ These children did not have hearing loss, were not diagnosed as autistic, no environmental factors were reported, no neurological or motor defect, and their nonverbal IQ tests were within normal range, but their language lagged behind their peers by a year or more, and had a deficit in expression (production) or comprehension (reception) of speech. The speech therapy sessions applies various models of treatment. Some of these were based on developmental milestones that follow the sequences of language acquisition in the aspects of cognition, linguistic and 


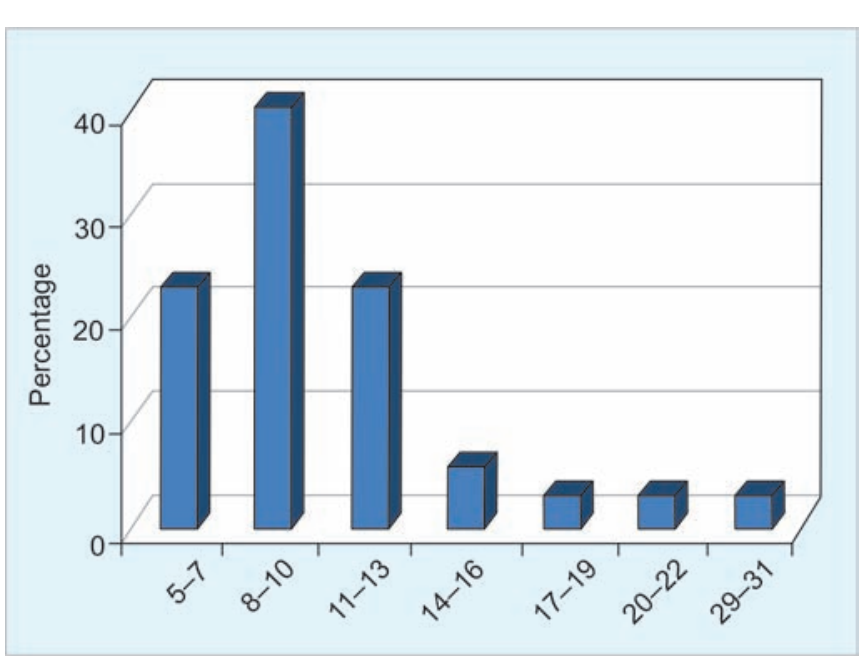

Graph 9: Age distribution of dyslexia cases

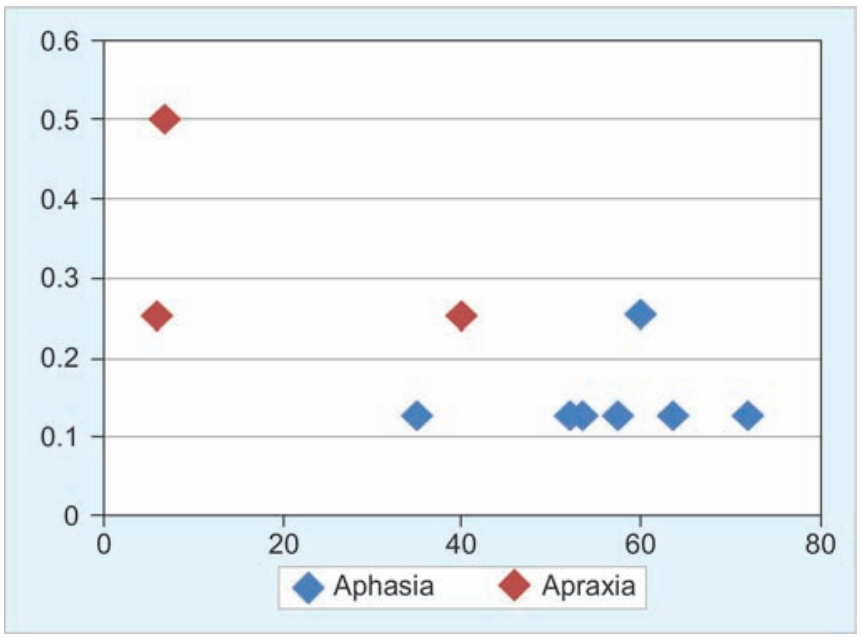

Graph 10: Age distribution of aphasia/apraxia cases

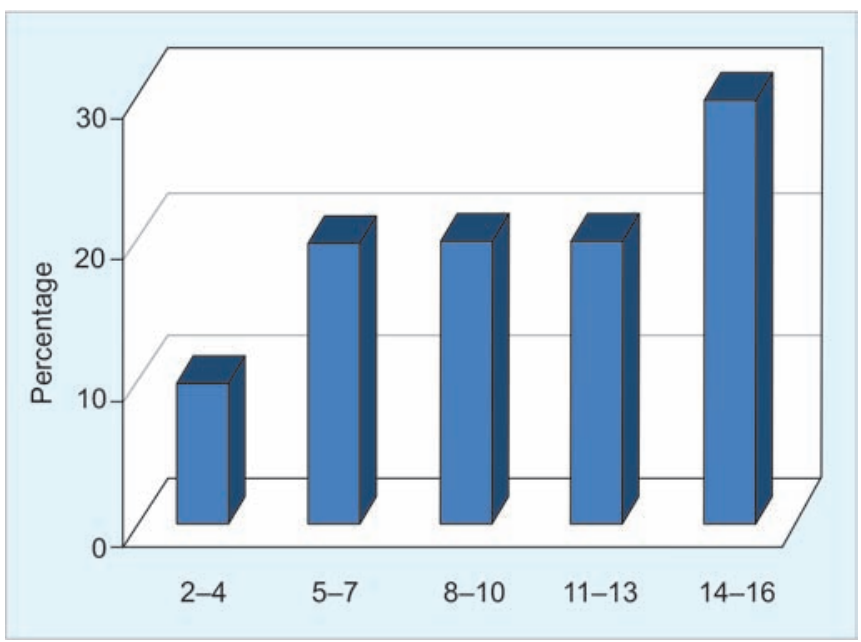

Graph 11: Age distribution of autism cases

pragmatic. A non-developmental approach was applied in atypical patterns of language acquisition as in children with mental retardation. ${ }^{3,12}$

In this study, the articulation disorders constituted about $19 \%$ of all CDs, which are very common speech problems, as reported in other studies. ${ }^{3,9}$ These disorders may occur either as an isolated problem or accompanied with other disorders, including language disorder, cerebral palsy (CP), MR, HIPs, and other neurological or orofacial abnormalities.

The treatment of articulation disorders is based on its cause, whether functional or organic. In the functional type, the therapy is targeted by developmental approach, according to the order of acquisition of speech sounds during development, or using the non developmental approach targeting the speech sounds relevant to child, which may be applied in adolescents and adults with articulation problem with ' $\mathrm{s}$ ' or ' $\mathrm{r}$ ' sounds. In organic articulation disorders, which occur in children with cleft palate, hearing impairment, the speech therapy method is by the non-developmental approach.,12,13

In this study, stuttering fell in the second place after DLD, with percent of $21 \%$, and a male to female ratio of 5 to 1 . A high prevalence of stuttering is also reported by other studies, and it may affect 4 to $5 \%$ of population between 2 and 4 years, and sex distribution is equal in ages 2 to 4 , and the ratio of boys to girls increase in persistent stuttering to a Figure of 3 to 1 as getting older. ${ }^{14}$ Stuttering, usually, starts in early childhood (between ages 2 and 4 years), and if untreated by SLPs, it may persist in most of the cases into adulthood. Speech therapy with stuttering or fluency disorder is based crucially on the age of the patient. In children, the indirect procedures of treatment are used, and the direct methods are used with older patients. The approaches of treatment are based on two schools, the fluency shaping school and the stuttering modification school. ${ }^{6,12}$

Speech problems due to hearing loss in this study, constituted $14 \%$. They usually presented with DLD, articulation disorder, and voice disorders (a change in pitch and quality). These children were usually fitted with hearing aids before voice and speech therapy. The SLPs used different options in the treatment of HIPs like auditory training, auditory-verbal training, and apply a therapy plan that focuses on detection, discrimination, identification and comprehension of speech. ${ }^{15}$

Most cases of MR in this study (8\%) were cases with Down syndrome, and they had language and articulation disorders. There are, usually, special centers for dealing with MR cases. Zimmerman et al reported $4 \%$ of the identified CDs with intellectual disability were in 8 years old school children. ${ }^{16}$

Voice/resonance problems form about $7 \%$ of CDs, which were dealt with SLPs. Most of the voice cases included vocal nodules, dysphonia and puberphonia; and nearly all cases of nasality problems were due to repaired cleft palate with velopharyngeal incompetence, which affects all aspects of speech, and manifested by audible nasal emission of air, hyper-nasal resonance, and 
articulation errors. Voice problems prevalence in other studies revealed a higher percentage than this study in the elderly (21\%), and in school-aged children with hoarseness of 6 to $23 \%{ }^{17}$

The main aim of treatment of voice disorders are based on production of a voice with almost normal pitch, loudness and quality in relation to the age and gender of the individual. The speech therapy techniques of voice disorders are designed for specific voice abnormalities, which are divided into four categories: vocal hyperfunction, vocal hypofunction, psychogenic disorders and spasmodic dysphonias. In some cases of organic voice disorders, the treatment is strictly medical, and in others a combination of medical and behavioral therapy. ${ }^{5}$

Dyslexia forms about $5 \%$ of all CDs population visiting the phonetic center and most of the dyslexia cases were of school age and a prevalence of $7 \%$ was reported by Tomblin et al in kindergarten children. ${ }^{18}$ Dyslexia is a difficulty with reading and writing, which are very complex processes that require great information to process very rapidly. For a dyslexic child, there are certain difficulties to read and write at the necessary speed, whilst dyslexia in adulthood refers usually to the difficulty in reading after a stroke or head injury or other traumas to the brain. ${ }^{19}$ The approach of treatment dyslexia in children is termed 'nuts and bolts' method, which is based on multisensory procedure and working with children at their own pace with segmenting and repetition of information. ${ }^{19}$

Cases with aphasia, apraxia or dysarthria were few relative to the other CDs forming about $2 \%$. Aphasia is language disorder result from brain damage, mostly due to cerebrovascular accident or stroke (CVA) and head injury. There are many types of aphasias, and the treatment approaches varies accordingly. Aphasia can be divided into two categories related to the quality of output, into nonfluent and fluent categories, with subtypes for each category. The aim of speech therapy is to improve the patient's communication to the highest possible level, and there are many approaches for this goal including, stimulation-facilitation, deblocking, operant conditioning, and functional/compensatory approaches. $^{7,12}$

Apraxia, unlike dysarthrias, is not associated with muscular impairment, but there is inability to plan and execute voluntary motor movements due to central nervous damage, and there may be limb, oral and verbal apraxias. The aim of treatment in apraxia is to improve intelligibility and motor control of speech, and in dysarthrias, many approaches are applied, such as behavior modification, prosthetic devices, medical and surgical procedures and augmentative/alternative devices as well as targeting the respiratory, phonatory, resonance and articulatory subsystems. ${ }^{7}$

Speech language pathologist may also be part of the multidisciplinary team involved with the diagnosis and treatment of children with autism. In this study, autism formed the least percentage of speech disorders (1\%), with equal male to female ratio, which is because there are many specialized centers to treat autistic children. In Utah State, it was found that autism spectrum disorder (ASD) constitutes $3.7 \%$ of CDs in 8 years old children. ${ }^{16}$ Autism is characterized by impairment in social communication and they are differentiated from the mentally retarded by their normal development of manipulative skill and even higher skills of solving puzzles, and it is 3 to 5 times more in males than in females. Autism can be treated using the methods of applied behavioral analysis for a minimum of 2 years training, 30 hours or more per week and delivered by individuals with extensive training in these methods. ${ }^{20}$ The behavior training should begin before the age of 5 and it was found that only $10 \%$ of these children gain little or no improvements despite intensive intervention. ${ }^{20}$

\section{CONCLUSION}

It seems clear that CDs are common problems that affect both sexes and the type of speech disorder varies with age; the peak of age presentation is in the preschool age group for the speech disorders DLD, stuttering, HIP, and nasality cases and in the school age groups for articulation, MR, dyslexia, autism and developmental apraxia. Voice problems and aphasia disorders mainly present in the middle age and elderly groups respectively.

\section{ACKNOWLEDGMENT}

The authors wish to thank the speech-language pathologists in the Phonetic Center/University of Jordan, for their kind cooperation to facilitate the research.

\section{REFERENCES}

1. Hegde MN. Introduction to communication disorders. 4th ed. Pro-Ed; 2009.

2. Reich PA. Language development. 1st ed. Prentice-Hall 1986.

3. Bleili KM. Manual of articulation and phonological disorders: infancy through childhood. Clinical Competence Series, 2nd ed. 2003.

4. Howell J, Dean E. Treating phonological disorders in children. 2nd ed. Wiley, 1994.

5. Rammage L, Morrison M, Nichol H. Management of the voice and its disorders. 2nd ed. Cengage Learning, 2000.

6. Guitar B. Stuttering: an integrated approach to its nature and treatment. 3rd ed. Williams and Wilkins, 2005.

7. Murdoch BE. Acquired speech and language disorders. 2nd ed. Wiley, 2009. 
8. Shipley KG, McAfee JG. Assessment in speech-language pathology: a resource manual. 4th ed. Cengage Learning, 2008.

9. Mckinnon DH. Prevalence of stuttering, voice, and speechsound disorders in primary school students in Australia. Language, speech, and hearing services in schools 2007;38: 5-15.

10. Nelson HD, et al. Screening for speech and language delay in preschool children: systematic evidence review for the US Preventive Services Task Force. Pediatrics 2006;117:298-319.

11. Beitchman JH, et al. Prevalence of speech and language disorders in 5 years old kindergarten children in the Ottawa-Carleton region. J Speech Hear Disord 1986;51: 98-110.

12. Worthington R. Treatment resource manual for speechlanguage pathology. 4th ed. Delmar Cengage Learning, 2010.

13. Al-Amayreh M. A normative study of the acquisition of consonant-sounds in Arabic, a dissertation presented to the graduate school of the University of Florida in partial fulfillment of the requirements for the degree of doctor of philosophy, 1994.

14. Zebrowski PM. Developmental stuttering. Pediatric Annals 2000;32:453-458.

15. Bench RJ. Communication skills in hearing impaired children. SAGE Publications, 1992.

16. Zimmerman JP, et al. Communication disorders: prevalence and comorbid intellectual disability, autism, and emotional/ behavioral disorders. Am J Speech-Language Pathol 2007; 16:359-367.

17. Faust RA. Childhood voice disorders: ambulatory evaluation and operative diagnosis. Clinical Pediatrics 2003;42:1-9.

18. Tomblin JB, et al. Prevalence of specific language impairment in Kindergarten children. J Speech Language Hearing Res 1997;40:145-160.

19. Cooke A. Tackling dyslexia: the Banger way. 1st ed. Whurr Publishers, 1993.

20. Maurice C. Behavioral intervention for young children with autism: a manual for parents and professionals. 1sted. Pro-ed, 1996. 